study 0f IgG4-related ophthalmic disease in Japan.JpnJOphthalmol.2013;57: 573-579.

[2] Shields JA et al. Survey of 1264 patients with orbital tumors and simulating lesions: the 2002 Montgomery Lecture, part I. Ophthalmology.2004;111: 997-1008.

[3] Goto $\mathrm{H}$ et al. Diagnostic criteria for IgG4-related ophthalmic disease. JpnJOphthalmol.2015;59:1-7.

Disclosure of Interest: None declared

DOI: 10.1136/annrheumdis-2017-eular.4309

\section{THU0579 HYPOCOMPLEMENTEMIA IS RELATED TO ELEVATED SERUM LEVELS OF IGG SUBCLASSES OTHER THAN IGG4 IN IGG4-RELATED KIDNEY DISEASE}

Y. Fujisawa, I. Mizushima, S. Tsuge, S. Hara, F. Suzuki, K. Ito, H. Fuji, K. Yamada, M. Kawano. Division of Rheumatology, Department of Cardiovascular and Internal Medicine, Kanazawa City, Japan

Background: IgG4-related kidney disease (IgG4-RKD) is a comprehensive term for renal lesions associated with IgG4-related disease [1]. IgG4-RKD is frequently complicated by hypocomplementemia [1, 2, 3], but its clinical significance and mechanisms have not been clarified.

Objectives: This study aimed to investigate clinical features of IgG4-RKD patients with hypocomplementemia compared with those without it, leading to clarification of the clinical significance and mechanisms of hypocomplementemia.

Methods: We extracted 25 patients with IgG4-RKD between September 2005 and December 2016 in our hospital. Based on the presence/absence of hypocomplementemia at diagnosis, we divided them into a hypocomplementemia group $(n=11)$ and normal complement group $(n=14)$, and retrospectively analyzed various clinical features (age, sex, serum IgG levels, serum IgG4 levels, gaps between serum IgG and IgG4 level, ratio of serum IgG to serum IgG4, serum IgG subclasses, serum lgE levels, serum creatinine levels, urinary protein and urinary occult blood, urinary $\beta 2$-microglobulin, urinary $\mathrm{N}$-acetyl- $\beta$-D-glucosaminidase, initial dose of prednisolone, serum IL-2R levels, multiple organ lesion) during the clinical course in the two groups.

Results: The patients comprised 18 men and 7 women with an average age of 67.5 years (range, 44 to 81 years). Serum lgG levels $(3971 \pm 729 \mathrm{mg} / \mathrm{dL}$ vs. $2157 \pm 598 \mathrm{mg} / \mathrm{dL} ; \mathrm{p}<0.001)$, gaps between serum lgG and lgG4 level $(2992 \pm 770$ $\mathrm{mg} / \mathrm{dL}$ vs. $1482 \pm 444 \mathrm{mg} / \mathrm{dL} ; \mathrm{p}<0.001)$, serum lgG1 levels $(2043 \pm 1025 \mathrm{mg} / \mathrm{dL}$ vs. $891 \pm 209 \mathrm{mg} / \mathrm{dL} ; \mathrm{p}=0.017)$, and the number of involved organs $(4.1 \pm 1.1 \mathrm{vs}$ $2.9 \pm 1.1 ; p=0.018$ ) were significantly different between the two groups, while serum IgG4 levels $(979 \pm 477 \mathrm{mg} / \mathrm{dL}$ vs. $791 \pm 575 \mathrm{mg} / \mathrm{dL} ; \mathrm{p}=0.298)$ and serum creatinine levels $(1.96 \pm 1.89 \mathrm{mg} / \mathrm{dL}$ vs. $1.09 \pm 0.48 \mathrm{mg} / \mathrm{dL} ; p=0.298)$ were not. At relapse of renal lesions, although both groups showed serum lgG4 re-elevation, the hypocomplementemia group showed exacerbation of hypocomplementemia and re-expansion of gaps between serum IgG and IgG4 level, while the normal complement group did not.

Conclusions: Hypocomplementemia may be associated with multiple organ involvement and elevation of IgG subclasses other than lgG4 including lgG1 in IgG4-RKD. In patients who initially show hypocomplementemia, a decline in serum complement levels implies renal lesion relapse.

References:

[1] Kawano $M$ et al. Proposal for diagnostic criteria for IgG4-related kidney disease. Clin Exp Nephrol. 2011 Oct;15(5):615-26.

[2] Saeki T et al. Clinicopathological characteristics of patients with lgG4-related tubulointerstitial nephritis. Kidney Int. 2010 Nov;78(10):1016-23.

[3] Raissian $Y$ et al. Diagnosis of IgG4-related tubulointerstitial nephritis. J Am Soc Nephrol. 2011 Jul;22(7):1343-52.

Disclosure of Interest: None declared

DOI: 10.1136/annrheumdis-2017-eular.4257

\section{THURSDAY, 15 JUNE 2017}

\section{Education}

\section{THU0580 WHAT ARE THE PATIENTS' ISSUES AND NEEDS RELATED TO THEIR BIOLOGICS (BDMARDS) AND METHOTREXATE (MTX) TREATMENT IN DAILY LIFE: A QUANTITATIVE CROSS-SECTIONAL SURVEY AMONG 344 PATIENTS TO DEVELOP AN EDUCATIONAL SMARTPHONE APP}

C. Beauvais ${ }^{1}$, S. Tropé ${ }^{2}$, A. Lafourcade ${ }^{3}$, D. Carnet $^{4}$, L. Grange ${ }^{5}$, L. Carton ${ }^{6}$,

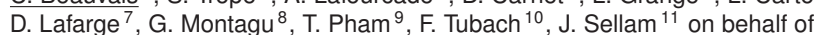
Therapeutic education section of the French Society of Rheumatology and Club Rhumatismes Inflammation. ${ }^{1}$ Rheumatology, Saint Antoine Hospital. APHP, Paris; ${ }^{2}$ Association ANDAR, Montpellier; ${ }^{3}$ Biostatistics, AP-HP Hôpital Pitié-Salpétrière, Paris; ${ }^{4}$ ANDAR, Montpellier; ${ }^{5}$ Rheumatology, Echirolles; ${ }^{6}$ Association AFLAR; ${ }^{7}$ Association AFS; ${ }^{8}$ Unknowns, Strategic and Innovation Consulting, Paris; ${ }^{9}$ Rheumatology, Hôpital Sainte-Marguerite, AP-HM, Marseille; ${ }^{10}$ Biostatistics, Public Health, and Medical Information, AP-HP Hôpital Pitié-Salpétrière; ${ }^{11}$ Reumatology, AP-HP St-Antoine, Univ Paris 06, Paris, France

Background: MTX and bDMARDs are the core treatments of chronic inflammatory arthritis (IA). We lack information on the patients' problems and needs in daily life, particularly on safety issues.

Objectives: 1-collect the most frequent issues 2-explore the patients' perceptions on a dedicated smartphone application (SP App) 3) determine the profile of the patients interested.

Methods: The survey was conducted on line. The questionnaire was designed by rheumatologists, methodologists, anthropologists, members of patients association (AP) and included 1-a non-exhaustive list of potential issues in daily life (fever, vaccines, ...) and practical aspects 2-a list of potential use of the App 3free opinions 4- Two self-administrated questionnaire to test patients' knowledge on bDMARDs [1] and MTX [2].

Results: The survey was carried out from June to August 2016 on the websites of the PA. Non-associative patients were recruited by 3 rheumatologists who provided the Internet link. 344 patients responded, 331 analyzed, $83 \%$ female, $50 \%$ had rheumatoid arthritis, $40 \%$ had spondyloarthritis, mean age 53 years, $60 \%$ were AP; $67 \%$ were treated with MTX, $70 \%$ had bDMARDs, $34 \%$ had MTXbDMARDs combotherapy.

$66 \%$ of patients reported problems; $67 \%$ had needed help or advice. The main issues were infections $(27 \%)$, vaccines $(13 \%)$, surgery $(10 \%)$, dental care $(7 \%)$, self-administration (6\%), conservation/travelling $(9 \%)$ and skipped doses $(5 \%)$. Among the $76 \%$ patients who have a SP, $80 \%$ use Apps and $32 \%$ Apps for their health. Among users, $87 \%$ patients would find an App useful to manage their treatment (36\% rather agree and $51 \%$ strongly agree), $82 \%$ for symptoms requiring to stop their treatment, $93 \%$ for situations related to safety, $80 \%$ as a reminder of their treatment, $80 \%$ to know what to do in case of a skipped dose, $77 \%$ to have a safety checklist before treatment administration, $66 \%$ to recall the modalities of self-injections. Patients interested in the App are younger $(p<0.05)$ non-associative $(p<0.05)$ and live in medium-sized cities $(p<0.01)$. No correlation was found with other sociodemographic characteristics, level of education, type/duration of arthritis or knowledge.

Conclusions: Two-third of patients with arthritis face issues related to their treatment especially in case of infections, vaccination, surgery and travelling. A dedicated App is considered useful by $87 \%$ patients who already have a SP. The potential use of the App may improve safety, adherence and self-management in daily life.

References:

[1] Gossec L et coll. Joint Bone Spine. 2013; Fayet F et coll J Clin Nurs. 2016. Acknowledgements: Grant: French Society of Rheumatology with the institutional funding by Biogen, Nordic Pharma, Roche.

Disclosure of Interest: None declared

DOI: 10.1136/annrheumdis-2017-eular.5549

\section{THU0581 WHAT WE SEE, WHAT WE LEARN, AND THE PREVALENCE OF RHEUMATIC DISEASES IN OUR POPULATION: A DIAGNOSIS CORRELATION STUDY}

D. Vega-Morales ${ }^{1}$, J.A. Esquivel-Valerio ${ }^{1}$, R. Ortiz-Lopez ${ }^{2}$, A.C. Arana-Guajardo ${ }^{1}$, M.A. Garza-Elizondo ${ }^{1} .{ }^{1}$ Rheumatology Service;

${ }^{2}$ Rheumatology, Hospital Universitario Dr. José Eleuterio González, Monterrey, Mexico

Background: The postgraduate program in rheumatology aims learning of musculoskeletal and autoimmune disorders. In México, objectively-structured clinical examination (OSCE) is applied in postgraduate certification processes by the Mexican Board of Rheumatology annually [1]. Peláez-Ballestas et al. described an epidemiological study (COPCORD, Community Oriented Program for the Control of Rheumatic Diseases) of 19,213 individuals in 5 regions in our country where they found a prevalence of musculoskeletal pain in $25.5 \%$, osteoarthritis in $10.5 \%$, back pain in $5.8 \%$, rheumatic regional pain syndromes in $3.8 \%$, rheumatoid arthritis (RA) in $1.6 \%$, and fibromyalgia in $0.7 \%$ [2].

Objectives: The aim of the study is to describe the student training in rheumatic diseases and correlate them with OSCE assessment and the prevalence of rheumatic diseases in our population.

Methods: An observational and analytical study was made between March 2014 to March 2015 in a single rheumatology training center at University Hospital. Student training was defined according to the times they evaluated patients with a determined diagnosis, this information was obtained by medical records. We categorize OSCE questions according to the rheumatic diagnosis. Finally, the two results were compared with prevalence of the rheumatic diagnosis according to COPCORD, which were registered according a score pain $>4$. We made descriptive statistics and a Spearman's Rho to evaluate the correlations of the diagnosis frequencies by each category.

Results: We reviewed 6279 medical records, 854 (13.6\%) were of first-time evaluation. We had $5,400(86.4 \%)$ women, with a mean age of 47.9 (SD 15.45) years.

Descriptive statistics are in Table 1 and Figure 1, which included: medical consultations, OSCE assessment and a column with rheumatologic diagnosis according to COPCORD.

The Spearman correlation coefficients of the 32 different diagnoses were: student training vs OSCE $0.492(p=0.004)$, student training vs COPCORD $0.597(p=0.01)$ and OSCE vs COPCORD $0.624(\mathrm{p}=0.01)$

Conclusions: Although the most common musculoskeletal disease in our community did not obtain the frequency observed by students or evaluated in 